\title{
Farelo da vagem de algaroba em dietas para cabras lactantes: parâmetros ruminais e síntese de proteína microbiana ${ }^{1}$
}

\section{Lizziane da Silva Argôlo², Mara Lúcia Albuquerque Pereira ${ }^{3}$, João Carlos Teixeira Dias 4 , Jurandir Ferreira da Cruz ${ }^{5}$, Antonio Jorge Del Rei ${ }^{6}$, Carlos Alberto Santana de Oliveira ${ }^{2}$}

\author{
1 Projeto financiado pela FAPESB. \\ ${ }^{2}$ Mestrado em Zootecnia-UESB. \\ ${ }^{3} D E B I / U E S B$, Itapetinga-BA. \\ ${ }^{4} D C B / U E S C$, Ilhéus-BA. \\ ${ }^{5}$ DFZ/UESB, Itapetinga-BA. \\ ${ }^{6}$ DTRA/UESB, Itapetinga-BA.
}

RESUMO - Objetivou-se avaliar os efeitos da adição de farelo da vagem de algaroba $(0 ; 33,3 ; 66,7$ e $100 \%)$ em substituição ao fubá de milho sobre a excreção de derivados de purina, estimada com coleta total de urina, e sobre os parâmetros ruminais ( $\mathrm{pH}$, amônia e ácidos graxos voláteis) de cabras em lactação. Utilizaram-se oito cabras adultas lactantes distribuídas em dois quadrados latinos $4 \times 4$ e alimentadas com dietas isoproteicas, compostas de $40 \%$ de silagem de capim-elefante e $60 \%$ de concentrado. Não houve efeito significativo da adição de farelo da vagem de algaroba sobre os parâmetros ruminais. $\mathrm{O}$ pH manteve-se em faixa adequada, entre 6,85 e 7,03, e a concentração média de nitrogênio amoniacal ruminal foi de $6,97 \mathrm{mg}$ de $\mathrm{N} / 100 \mathrm{~mL}$ de fluido ruminal. As concentrações de acetato e propionato variaram de 9,47 a 10,54 e de 4,79 a $6,58 \mathrm{mM}$, respectivamente. As excreções (mmol/dia) de alantoína, ácido úrico, xantinahipoxantina, a quantidade (mmol/dia) de purinas absorvidas, o fluxo intestinal (g/dia) de nitrogênio microbiano e a eficiência de síntese microbiana (PM/kg NDT) apresentaram resposta linear negativa à substituição do fubá de milho pelo farelo da vagem de algaroba. A estimativa da síntese de proteína microbiana em cabras deve ser calculada pela excreção de derivados de purinas a partir de equações obtidas com caprinos.

Palavras-chave: caprinos, derivados de purinas, fermentação ruminal, Prosopis juliflora, proteína microbiana

\section{Mesquite pod meal in diets of lactating goats: ruminal parameters and microbial efficiency synthesis}

\begin{abstract}
The objective of this study was to evaluate the effect of adding mesquite pod meal $(0,33.3,66.7$ and $100 \%)$ to substitute corn meal on purin derivative the excretion, estimated by total urine collection, and on the ruminal parameters $(\mathrm{pH}$, ammonia and volatile fatty acids). Eight lactating goats were used and distributed in a $4 \times 4$ Latin square and fed iso-protein diets consisting of $40 \%$ elephant grass silage and $60 \%$ concentrate. There was no significant effect from adding mesquite pod meal on the ruminal parameters. The $\mathrm{pH}$ ranged from 6.85 to 7.03 and the ruminal ammonia concentration averaged $6.97 \mathrm{mg} / 100 \mathrm{~mL}$. The acetate and propionate concentrations ranged from 9.47 to 10.54 and 4.79 to $6.58 \mathrm{mM}$, respectively. The excretion (mmol/day) of allantoin, uric acid and xanthine-hypoxanthine, the quantity of absorbed purines, the nitrogen microbial intestinal flow (g/day), microbial nitrogen synthesis (g/day) and efficiency of microbial protein synthesis efficiency, expressed in $\mathrm{g}$ of microbial crude protein $/ \mathrm{kg}$ of the total digestible nutrients, presented linear negative response to corn replacement with mesquite pod meal. Microbial synthesis in goats must be estimated by the purine derivatives excretion using equations obtained from goats
\end{abstract}

Key Words: goats, microbial protein, purine derivatives, Prosopis juliflora, ruminal fermentation

\section{Introdução}

A alimentação dos animais representa o maior custo da atividade pecuária (Martins et al., 2000), principalmente quando se usam grãos tradicionais, como o milho e o trigo. Dessa forma, torna-se necessária a utilização de fontes alimentares alternativas com melhor relação custo/ benefício. Alimentos disponíveis regionalmente surgem como alternativas viáveis, tanto do ponto de vista nutricional como econômico, assim, o farelo da vagem de algaroba é utilizado na Região Nordeste em substituição ao milho, pois a algarobeira resiste às condições

Recebido em 29/3/2008 e aprovado em 20/3/2009.

Correspondências devem ser enviadas para: mara@uesb.br 
edafoclimáticas do semiárido e produz grande quantidade de vagem.

As quantidades de carboidratos solúveis, conforme Valadares Filho et al. (2006), são de 54,16 e 19,90\% para o farelo da vagem de algaroba e o fubá de milho, respectivamente.

A fermentação ruminal pode ser caracterizada quantitativamente pelas concentrações e proporções relativas dos produtos da fermentação, pela eficiência de síntese de proteína microbiana e pela quantidade de matéria orgânica (MO) fermentada (Nagaraja et al., 1997). Os componentes intermediários da fermentação da matéria orgânica também servem de monômeros para síntese de material celular. Entretanto, existe uma relação inversa entre produção de ácidos graxos voláteis e síntese de célula microbiana.

A fermentação da pectina está relacionada à elevação da concentração de acetato, enquanto o amido e os açúcares, geralmente aumentam a proporção de ácido propiônico e butírico, aspectos relacionados à alteração no percentual de gordura láctea (Belisakis \& Tsirgogianni, 1996).

A proteína microbiana sintetizada no rúmen é a maior e mais barata fonte proteica para ruminantes. Em áreas onde a disponibilidade de suplementação é escassa, o aumento da produção de proteína microbiana por meio de um programa de arraçoamento, baseado em alimentos concentrados regionalmente disponíveis é uma forma efetiva e sustentável para melhoria da produtividade dos ruminantes.

Neste contexto, e por serem escassos estudos envolvendo caprinos e alimentos não-convencionais, conduziu-se este trabalho com o objetivo de avaliar o efeito da substituição do fubá de milho pelo farelo da vagem de algaroba no concentrado sobre a produção de proteína microbiana em cabras lactantes, estimada pela técnica da excreção urinária de derivados de purinas, com coleta total de urina, somada à secreção de alantoína no leite, e sobre os parâmetros ruminais ( $\mathrm{pH}$, concentração de nitrogênio amoniacal e relação acetato: propionato).

\section{Material e Métodos}

Foram utilizadas oito cabras da raça Saanen, com aproximadamente 60 dias de lactação e peso vivo médio de $50 \mathrm{~kg}$ e escore corporal 3, confinadas em baias individuais com dimensões de 1,5 × 1,0 m com piso ripado de madeira.

Os animais foram distribuídos em dois quadrados latinos balanceados $4 \times 4$ para avaliação dos efeitos da utilização de farelo da vagem de algaroba em dietas isoproteicas, tendo como volumoso a silagem de capim-elefante na proporção de $40 \%$. A substituição do fubá de milho pelo farelo de vagem de algaroba no concentrado foi a variável independente utilizada para caracterizar os tratamentos, constituídos de quatro níveis $(0 ; 33,3 ; 66,7$ e $100 \%$ na matéria natural) de farelo de vagem de algaroba em substituição ao milho (Tabela 1).

$\mathrm{O}$ experimento foi constituído de quatro períodos experimentais, cada um com 17 dias de duração: os dez primeiros de adaptação e os sete dias restantes de coletas de dados. Com acesso à vontade ao alimento e à água, as cabras foram alimentadas às 8 e às $16 \mathrm{~h}$, em quantidade suficiente para garantir $10 \%$ de sobras.

Para determinação da concentração de amônia $\left(\mathrm{N}-\mathrm{NH}_{3}\right)$ e ácidos graxos voláteis (AGV) no rúmen, amostras de líquido ruminal foram coletadas utilizando-se sonda esofágica adaptada a uma bomba de vácuo e o líquido ruminal foi filtrado utilizando-se gaze dobrada em quatro camadas, no 17으 dia de cada período experimental, 6 horas após a alimentação da manhã. $\mathrm{O}$ pH foi mensurado imediatamente após a coleta do material, com potenciômetro digital. Para análise de amônia e ácidos graxos voláteis, as amostras foram acidificadas com ácido fosfórico $25 \%$ imediatamente após a coleta $(1 \mathrm{~mL}$ de ácido: $5 \mathrm{~mL}$ fluido), foram centrifugadas a $13.400 \mathrm{rpm}$ (rotação por minuto) por 10 minutos e o sobrenadante foi filtrado com membrana de $0,2 \mu \mathrm{m}$ de porosidade e em seguida mantido em freezer a $-20^{\circ} \mathrm{C}$.

Tabela 1 - Composição das dietas experimentais

\begin{tabular}{lcccc}
\hline & \multicolumn{3}{c}{$\begin{array}{c}\text { Nível de farelo da vagem de } \\
\text { algaroba }(\% \text { matéria }\end{array}$} \\
\cline { 2 - 5 } & 0 & 33,3 & 66,7 & 100 \\
\cline { 2 - 5 } & & & & \\
Ingrediente (\% MN concentrado) & & & \\
Fubá de milho & 78,10 & 52,51 & 26,48 & 0,00 \\
Farelo de algaroba & 0,00 & 25,42 & 51,28 & 77,60 \\
Farelo de soja & 13,3 & 13,24 & 13,19 & 13,13 \\
Farelo de algodão & 4,92 & 4,96 & 5,00 & 5,05 \\
Mistura mineral & 3,68 & $3,85^{2}$ & $4,03^{3}$ & 4,204 \\
Matéria seca (dietas) & 65,48 & 65,76 & 66,63 & 66,99 \\
Nutriente (\% MS) & & & & \\
Matéria orgânica & 90,68 & 90,39 & 89,91 & 88,93 \\
Proteína bruta & 9,55 & 9,49 & 9,35 & 9,29 \\
Extrato etéreo & 3,36 & 2,74 & 2,50 & 2,12 \\
Fibra em detergente neutro & 48,47 & 50,68 & 52,60 & 53,64 \\
Fibra em detergente ácido & 29,22 & 31,42 & 34,87 & 37,58 \\
Carboidratos não-fibrosos & 30,08 & 28,26 & 26,27 & 24,7 \\
Carboidratos totais & 77,95 & 78,34 & 78,26 & 80,46 \\
Nutrientes digestíveis totais & 68,58 & 69,34 & 67,17 & 68,16 \\
\hline
\end{tabular}

${ }^{1}$ Fosfato bicálcico $39,9 \%$, Sal comum 20,1\%, Sal mineral comercial 40,0\%.

${ }^{2}$ Fosfato bicálcico $42,3 \%$, Sal comum $19,2 \%$, Sal mineral comercial $38,5 \%$.

${ }^{3}$ Fosfato bicálcico 44,4\%, Sal comum 18,6\%, Sal mineral comercial 37,0\%.

${ }^{4}$ Fosfato bicálcico $46,4 \%$, Sal comum $17,9 \%$, Sal mineral comercial $35,7 \%$. 
Ao final do experimento, as amostras foram descongeladas e a concentração de $\mathrm{N}-\mathrm{NH}_{3}$ obtida após destilação com $\mathrm{KOH} 2 \mathrm{~N}$, conforme técnica descrita por Vieira(1980).

A determinação e a quantificação de ácidos graxos voláteis foram realizadas por cromatografia líquida de alta performance (HPLC). Alíquotas de $100 \mu \mathrm{L}$ de cada amostra foram aplicadas em coluna de exclusão iônica Bio-Rad Aminex HPX-87H, $300 \times 7,8 \mathrm{~mm}$ em fluxo de $0,7 \mathrm{~mL} /$ minuto, por uma solução aquosa móvel de $4 \mathrm{mM}$ de $\mathrm{H}_{2} \mathrm{SO}_{4}$ a $25^{\circ} \mathrm{C}$ no HPLC, para análise e detecção dos ácidos acético e propiônico. Os dados de cromatografia foram integrados e analisados com o software UNICORNTM v.5,0. Os ácidos acético e propiônico foram mensurados a $210 \mathrm{~nm}\left(R_{\mathrm{t}}=14,2\right)$. Alíquotas desses ácidos com concentrações conhecidas $(1,0 ; 0,5 ; 0,25 ; 0,125 ; 0,0625 ; 0,0312 \mathrm{mM})$ foram usadas para construção da curva-padrão e para verificar as similaridades com as concentrações obtidas das amostras.

Para estimar a síntese microbiana ruminal, as análises de derivados de purinas (alantoína, ácido úrico, xantinahipoxantina) foram realizadas nas amostras de urina e de leite, conforme metodologias descritas por Chen \& Gomes (1992).

As amostras de leite foram coletadas com base em duas ordenhas diárias e em quatro amostragens durante o período de coleta: ordenha vespertina no primeiro dia; ordenha da manhã no segundo dia; ordenha da tarde no quinto dia; e ordenha da manhã no sexto dia e agrupadas em amostras compostas proporcionais a $10 \%$ da produção de cada ordenha (tarde/ manhã). Uma alíquota de $10 \mathrm{~mL}$ de cada amostra composta foi retirada, misturada a $5 \mathrm{~mL}$ de ácido tricloroacético a $25 \%$, filtrada em papel-filtro e armazenada a $-20^{\circ} \mathrm{C}$ para posteriores análises de alantoína.

As coletas totais de urina foram realizadas no $6^{0}$ dia do período de coleta. Por meio de cateterismo, utilizando sonda de Foley 10, a urina foi coletada em galões plásticos de $5 \mathrm{~L}$ contendo $20 \mathrm{~mL}$ de $\mathrm{H}_{2} \mathrm{SO}_{4}$ a $40 \%$ e, ao final de cada coleta, foi pesada, homogeneizada e filtrada em gaze, retirando-se uma alíquota de $10 \%$ do volume diário em cada período.

Alíquotas de $10 \mathrm{~mL}$ das amostras foram diluídas em $40 \mathrm{~mL} \mathrm{He}_{2} \mathrm{SO}_{4}$ a $0,036 \mathrm{~N}$ e elaboradas com $\mathrm{pH}$ abaixo de 3 para evitar a destruição bacteriana dos derivados de purina urinários e a precipitação de ácido úrico. Posteriormente, foram armazenadas a $-20^{\circ} \mathrm{C}$ e submetidas a análises de alantoína, xantina-hipoxantina e ácido úrico, como descrito por Chen \& Gomes (1992).

A excreção total de derivados de purina foi calculada pela soma das quantidades de alantoína, ácido úrico, xantina e hipoxantina presentes na urina e alantoína secretada no leite e expressas em mmol/dia. As purinas absorvidas ( $\mathrm{X}, \mathrm{mmol} / \mathrm{dia}$ ) foram estimadas a partir da excreção de derivados de purina (Y, mmol/ dia), pela equação proposta por Chen \& Gomes (1992) para ovinos:

$$
\mathrm{Y}=0,84 \mathrm{X}+\left(0,150 \mathrm{PV}^{0,75} \mathrm{e}^{-0,25 \mathrm{X}}\right)
$$

em que: $0,84=$ eficiência de absorção de purinas exógenas; $0,150 \mathrm{PV}^{0,75}=$ excreção endógena de derivados de purina; e $\mathrm{e}^{-0,25 \mathrm{X}}=$ taxa de substituição da síntese de novo por purinas endógenas.

A síntese ruminal de proteína microbiana ( $\mathrm{g} \mathrm{NM} / \mathrm{dia}$ ) foi calculada em função das purinas absorvidas (X, mmol/dia), utilizando-se a equação descrita por Chen \& Gomes (1992):

$\mathrm{NM}=$

$$
0,83 \times 0,116 \times 1000
$$

em que 70 = conteúdo de nitrogênio de purinas ( $\mathrm{mg} \mathrm{N} / \mathrm{mmol})$; 0,83 = digestibilidade das purinas microbianas; e 0,116 = relação $\mathrm{N}$ purina: $\mathrm{N}$ total nas bactérias.

Foram empregadas também as equações propostas por Belenguer et al. (2002) para caprinos, nas quais a quantidade de purinas absorvidas (X, mmol/dia) pode ser estimada como a excreção de derivados de purina (Y) dividida pela taxa de recuperação de purinas $(0,76)$ :

$$
X=\frac{Y}{0,76}
$$

Belenguer et al. (2002) propuseram a seguinte equação:

$$
\mathrm{NM}(\mathrm{g} / \mathrm{d})=\frac{\mathrm{X}}{(0,92 \times 1,97)}
$$

em que $0,92=$ digestibilidade verdadeira das bases purinas no duodeno; e 1,97 ( $\mathrm{mmol}$ de bases purinas/ $\mathrm{g} \mathrm{N}$ ) = razão entre as bases purinas ( $164 \mathrm{mmol} / \mathrm{g}$ MS ) e conteúdo de $\mathrm{N}(83,8 \mathrm{mg} / \mathrm{g} \mathrm{MS})$ da população microbiana extraída do rúmen de cabras.

Os resultados foram avaliados por meio de análises de variância e regressão, utilizando-se o Sistema de Análises Estatísticas e Genéticas - SAEG 8.0 (Ribeiro Jr., 2001). Os critérios utilizados para escolha dos modelos foram os coeficientes de determinação $\left(\mathrm{r}^{2}\right)$ e a significância pelo teste F, a $5 \%$ de probabilidade. As médias de estimativa da síntese de proteína microbiana calculada pelos modelos de Belenguer et al. (2002) e Chen \& Gomes (1992) foram comparadas aplicando-se o teste t pareado.

\section{Resultados e Discussão}

Não houve influência da substituição do fubá de milho pelo farelo de vagem de algaroba no concentrado $(\mathrm{P}>0,05)$ sobre o $\mathrm{pH}$ (Tabela 2). Os resultados observados para $\mathrm{pH}$ ruminal estão na faixa de 6,85 a 7,03 e podem ser considerados normais para degradação de parede celular. Entretanto, foram superiores aos valores obtidos por Lana et al. (2007), de 6,6 a 5,6 no decorrer de 9 horas após a alimentação 
quando forneceram a cabras multíparas e secas uma dieta contendo $67 \%$ de silagem de milho e $33 \%$ de concentrado à base de fubá de milho e um aditivo alimentar à base própolis. Lana et al. (2007) observaram que, na maior parte do tempo, o pH manteve-se acima de 5,9 e obtiveram média de 6,2 .

A concentração média de amônia ruminal foi de $6,97 \mathrm{mg}$ de $\mathrm{N}-\mathrm{NH}_{3} / 100 \mathrm{~mL}$ de fluido ruminal e o valor mínimo obtido, de $6,60 \mathrm{mg} / 100 \mathrm{~mL}$ (Tabela 2). A substituição de fubá de milho pelo farelo de vagem de algaroba não influenciou essa variável. Os valores de $\mathrm{N}-\mathrm{NH}_{3}$ para todos os níveis de farelo de vagem de algaroba foram maiores que $5 \mathrm{mg}$ de $\mathrm{N}-\mathrm{NH}_{3} / 100 \mathrm{~mL}$ de líquido ruminal, nível mínimo necessário para manter as funções normais do rúmen como sugerido por Satter \& Slyter (1974).

As concentrações relativas de acetato e de propionato em $\mathrm{mM}$ (Figura 1) indicam que as dietas com farelo de vagem de algaroba resultaram em maior concentração de acetato que de propionato. Embora a adição desse alimento tenha reduzido a relação acetato:propionato em comparação à dieta sem farelo de vagem de algaroba, não houve efeito estatístico $(\mathrm{P}>0,05)$, o que pode estar relacionado ao elevado coeficiente de variação. A técnica de coleta de líquido ruminal por sonda esofagiana é válida, mas, sempre que se reduz o número de coletas, amplia-se a variação aleatória (Figura 1). Entretanto, há evidências de redução da relação acetato:propionato pela adição de farelo de vagem de algaroba.

Embora não tenha havido efeito sobre o perfil de ácidos graxos voláteis, a relação acetato:propionato (Tabela 2) sugere que o efeito da alta proporção de concentrado se sobrepôs ao da adição de algaroba. No farelo de vagem de algaroba, o amido (11-17\%) não é o principal componente energético, mas sim os mono e oligossacarídeos (28\%) somados aos ácidos orgânicos e à pectina (20\%). De acordo com o Cornell Net Carbohydrate and Protein System (Fox et al., 1992; Russell et al., 1992; CNCPS, 2002), os açúcares e ácidos orgânicos pertencem à fração $\mathrm{A}$, de rápida degradação ruminal. Todavida, o amido representa 91,45\% dos carboidratos não-estruturais do fubá de milho e pertence à fração B1, de degradação intermediária, da mesma forma que a pectina. Figueiredo et al. (2007) relataram valor da fração A + B1 (59,92\%) do farelo de vagem de algaroba inferior ao do milho $(72,20 \%)$ e, para as frações B2 $(16,52 \%)$ e $\mathrm{C}(10,57 \%)$, superiores ao do milho $(12,0 \% \mathrm{e}$ $0,38 \%)$, respectivamente.

Os microrganismos produzem mais propionato quando o amido é fermentado, mais acetato a partir de substâncias pécticas e mais butirato a partir da sacarose (Strobel \& Russell, 1986). Independentemente da fonte, o efeito do carboidrato no $\mathrm{pH}$ ruminal será, provavelmente, mais intimamente relacionado à sua taxa de produção de ácidos orgânicos (Leiva et al., 2000). Neste estudo, o farelo de vagem de algaroba não afetou as concentrações de acetato + propionato, o que provavelmente refletiu na semelhança dos valores de $\mathrm{pH}$ no rúmen.

Neste estudo as concentrações de acetato variaram de 9,47 a 10,54 mM e as de propionato, de 4,79 a 6,58 mM e foram inferiores aos valores relatados na literatura. Valores semelhantes foram obtidos por Guerrero-Cervantes et al. (2007), que, em pesquisa com leguminosas do semiárido do México, comumente selecionadas pelos caprinos da região, entre elas, uma espécie do gênero Prosopis, observaram

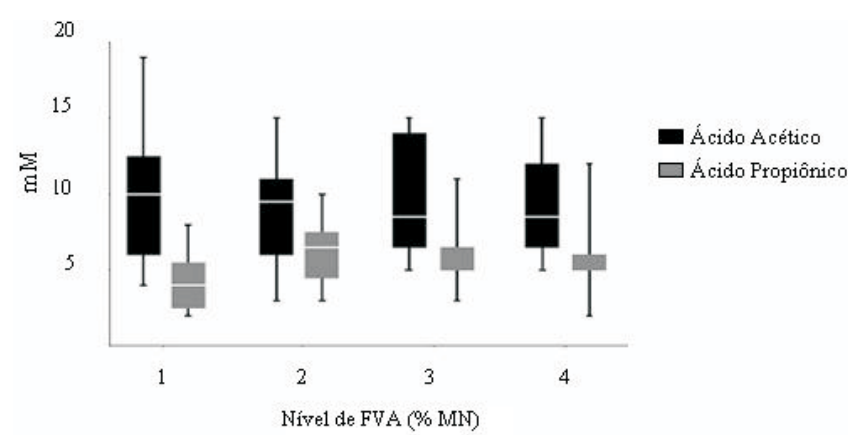

Figura 1 - Concentrações de acetato e propionato em cabras lactantes alimentadas com concentrado contendo farelo de vagem de algaroba em substituição ao fubá de milho.

Tabela 2 - pH ruminal e concentrações de nitrogênio amoniacal, acetato e propionato em cabras alimentadas com concentrado contendo farelo de vagem de algaroba em substituição ao fubá de milho

\begin{tabular}{|c|c|c|c|c|c|c|}
\hline \multirow[t]{2}{*}{ Item } & \multicolumn{4}{|c|}{ Nível de farelo de vagem de algaroba $(\% \mathrm{MN})$} & \multirow[t]{2}{*}{$\mathrm{CV} \%$} & \multirow[t]{2}{*}{ Regressão* } \\
\hline & 0 & 33,3 & 66,7 & 100 & & \\
\hline $\mathrm{pH}$ & 7,03 & 6,89 & 6,85 & 7,02 & 3,35 & $\hat{Y}=6,95$ \\
\hline $\mathrm{N}-\mathrm{NH}_{3}(\mathrm{mg} / 100 \mathrm{~mL})$ & 6,96 & 7,16 & 7,14 & 6,60 & 36,99 & $\hat{\mathrm{Y}}=6,97$ \\
\hline Acetato $(\mathrm{mM})$ & 10,54 & 9,47 & 10,02 & 9,76 & 33,82 & $\hat{\mathrm{Y}}=9,95$ \\
\hline Propionato $(\mathrm{mM})$ & 4,79 & 6,58 & 6,55 & 6,37 & 39,61 & $\hat{\mathrm{Y}}=6,07$ \\
\hline Acetato:propionato $(\mathrm{mM})$ & 2,49 & 1,52 & 1,58 & 1,72 & 50,38 & $\hat{\mathrm{Y}}=1,83$ \\
\hline
\end{tabular}

* não-significativo $(\mathrm{P}>0,05)$. 
valores de 9,49 e 3,13 $\mathrm{mM}$ para acetato e propionato, respectivamente.

A partir das amostras de coleta total de urina, durante um período de 24 horas, foi mensurado o volume urinário total por animal e estatisticamente a excreção urinária não diferiu entre os níveis de farelo de vagem de algaroba $(\hat{\mathrm{Y}}=1,95 ; \mathrm{P}>0,05)$.

Notou-se queda linear nas excreções de alantoína, ácido úrico, xantina e hipoxantina e derivados de purinas totais a partir de amostras de coleta total de urina em resposta aos níveis de substituição do fubá de milho pelo farelo de vagem de algaroba (Tabela 3 ).

A porcentagem média de alantoína excretada situou-se num intervalo estreito, de 65,25 a 67,37\%, em relação aos derivados de purina, enquanto a de ácido úrico foi de 6,11 a $6,76 \%$ e a de xantina e hipoxantina, entre 26,09 e $28,33 \%$ (Tabela 3). Os valores de alantoína encontrados neste estudo estão próximos aos citados por Fonseca et al. (2006) para cabras leiteiras, que encontraram variação de 64,5 a $75,9 \%$ na porcentagem média de alantoína.

Valor de ácido úrico superior ao deste estudo foi observado por Fonseca et al. (2006), que relataram proporção média de 9,6 a 19,9\%. No entanto, a proporção média relativa de xantina e hipoxantina foi superior à citada por esses autores, de 5,2 e 15,6\%. Os dados de ácido úrico, xantina e hipoxantina obtidos neste experimento divergem daqueles reportados por Lindberg (1989), que observou porcentagens de 13 a 33\% para ácido úrico e 10 a $13 \%$ para xantina e hipoxantina em cabritos em aleitamento.

Semelhantemente ao obtido por Fonseca et al. (2006), a secreção de alantoína no leite não foi influenciada $(\mathrm{P}>0,05)$ pelos níveis de farelo de vagem de algaroba no concentrado e não acompanhou a tendência observada na excreção urinária de alantoína e de derivados de purina. Estes dados sugerem que a secreção de alantoína no leite não é adequada para estimar a síntese de proteína microbiana em cabras.

A quantidade de purinas absorvidas, expressa em $\mathrm{mmol} /$ dia, reduziu de forma linear com a substituição do fubá de milho pelo farelo de vagem de algaroba, independentemente da equação utilizada (Tabela 4). A estimativa da quantidade de purinas absorvidas pela equação proposta por Chen \& Gomes (1992) foi inferior $(\mathrm{P}<0,01)$, pelo teste t pareado, àquela calculada pela equação de Belenguer et al. (2002), resultado consistente com os valores observados por Andrade-Montemayor et al. (2004) e Fonseca et al. (2006).

O fluxo intestinal de N-microbiano estimado pela equação de Chen \& Gomes (1992), no entanto, foi superior $(\mathrm{P}<0,01)$ àquele estimado pela equação de Belenguer et al. (2002) (Tabela 4), o que está de acordo com os resultados encontrados por Andrade-Montemayor et al. (2004) e Fonseca et al. (2006). A divergência entre os resultados referentes à quantidade de purinas absorvidas e fluxo de $\mathrm{N}$-microbiano obtidos com as equações possivelmente se

Tabela 3 - Excreções de alantoína, ácido úrico, xantina e hipoxantina e derivados de purina observadas em cabras lactantes alimentadas com concentrado contendo farelo de vagem de algaroba em substituição ao fubá de milho

\begin{tabular}{|c|c|c|c|c|c|c|c|}
\hline \multirow[t]{2}{*}{ Item } & \multicolumn{4}{|c|}{ Nível de farelo de vagem de algaroba $(\% \mathrm{MN})$} & \multirow[t]{2}{*}{$\mathrm{CV} \%$} & \multirow[t]{2}{*}{$r^{2}$} & \multirow[t]{2}{*}{ Regressão } \\
\hline & 0 & 33,3 & 66,7 & 100 & & & \\
\hline Alantoína na urina (mmol/dia) & 12,51 & 11,47 & 9,72 & 8,73 & 34,78 & 0,99 & $\hat{\mathrm{Y}}=12,57-0,039 * \mathrm{X}$ \\
\hline Alantoína na urina $(\%)$ & 67,37 & 65,73 & 65,25 & 65,61 & 7,16 & - & $\hat{\mathrm{Y}}=65,99$ \\
\hline Ácido úrico (mmol/dia) & 1,21 & 1,18 & 0,96 & 0,81 & 33,05 & 0,94 & $\hat{\mathrm{Y}}=1,25-0,0042 * * \mathrm{X}$ \\
\hline Ácido úrico $(\%)$ & 6,54 & 6,76 & 6,42 & 6,11 & 34,58 & - & $\hat{\mathrm{Y}}=6,46$ \\
\hline Xantina e hipoxantina (mmol/dia) & 4,84 & 4,80 & 4,22 & 3,76 & 29,94 & 0,92 & $\hat{\mathrm{Y}}=4,97-0,0011 * \mathrm{X}$ \\
\hline Xantina e hipoxantina (\%) & 26,09 & 27,50 & 28,33 & 28,28 & 12,13 & - & $\hat{\mathrm{Y}}=27,55$ \\
\hline Derivados de purina (mmol/dia) & 18,93 & 17,80 & 15,27 & 13,58 & 31,0 & 0,98 & $\hat{\mathrm{Y}}=19,18-0,056 * \mathrm{X}$ \\
\hline Alantoína no leite (mmol/dia) & 0,36 & 0,36 & 0,38 & 0,28 & 16,25 & - & $\hat{\mathrm{Y}}=0,34$ \\
\hline
\end{tabular}

** e * Significativo, respectivamente, a 1 e $5 \%$ de probabilidade pelo teste $\mathrm{F}$.

Tabela 4 - Equações de regressão ajustadas para a quantidade de purinas absorvidas e o fluxo intestinal de nitrogênio microbiano em cabras lactantes alimentadas com concentrado contendo farelo da vagem de algaroba em substituição ao fubá de milho

\begin{tabular}{|c|c|c|c|c|c|c|c|}
\hline \multirow[b]{2}{*}{ Item } & \multicolumn{4}{|c|}{ Nível de farelo de vagem de algaroba (\% MN) } & \multirow[b]{2}{*}{$\mathrm{CV} \%$} & \multirow[b]{2}{*}{$\mathrm{r}^{2}$} & \multirow[b]{2}{*}{ Equação Ajustada } \\
\hline & 0 & 33,3 & 66,7 & 100 & & & \\
\hline Purinas absorvidas 1 & 22,52 & 21,17 & 17,95 & 15,97 & 32,35 & 0,98 & $\hat{\mathrm{Y}}=22,83-0,068 * \mathrm{X}$ \\
\hline Purinas absorvidas ${ }^{2}$ & 24,91 & 23,42 & 20,10 & 17,87 & 31,0 & 0,98 & $\hat{\mathrm{Y}}=25,23-0,073 * \mathrm{X}$ \\
\hline Nitrogênio microbiano ${ }^{1}$ & 16,37 & 15,39 & 13,05 & 11,61 & 32,35 & 0,98 & $\hat{\mathrm{Y}}=16,60-0,050 * \mathrm{X}$ \\
\hline Nitrogênio microbiano ${ }^{2}$ & 13,74 & 12,92 & 11,09 & 9,86 & 31,0 & 0,98 & $\hat{\mathrm{Y}}=13,92-0,040 * \mathrm{X}$ \\
\hline
\end{tabular}

* Significativo a $5 \%$ de probabilidade pelo teste $\mathrm{F}$.

${ }^{1}$ Chen \& Gomes (1992); ${ }^{2}$ Belenguer et al. (2002). 
deve à digestibilidade considerada na elaboração das equações. Chen \& Gomes (1992) e Belenguer et al. (2002) consideram digestibilidades de 83 e $92 \%$, respectivamente. Além disso, Andrade-Montemayor et al. (2009) relataram que a estimativa do fluxo de $\mathrm{N}$-microbiano depende sobretudo da digestibilidade de purinas absorvidas no duodeno e que a razão entre o conteúdo de N-microbiano do rúmen e purinas absorvidas não é absoluta e pode variar de acordo com a dieta experimental. Andrade-Montemayor et al. (2004) afirmaram que os modelos propostos por Chen \& Gomes (1992) poderiam superestimar o fluxo de $\mathrm{N}$-microbiano em caprinos, informação que pode ser aceita neste estudo, visto que Belenguer et al. (2002) propuseram um modelo específico para caprinos e Chen \& Gomes (1992), um modelo para ovinos.

A substituição do fubá de milho pelo farelo de vagem de algaroba diminuiu linearmente $(\mathrm{P}<0,05)$ o fluxo de N-microbiano. Segundo Yu et al. (2002), as excreções de alantoína, ácido úrico, xantina e hipoxantina podem ser afetadas pela fonte de proteína dietética, pela fonte de energia, pelos consumos de MS, energia e proteína, pelo peso vivo, pelos aditivos alimentares e pelas espécies.

Neste estudo, a redução das excreções de alantoína, ácido úrico e xantina + hipoxantina pode está relacionada à redução linear do consumo de carboidratos não-fibrosos nas dietas com farelo de vagem de algaroba como fonte de energia (Tabela 5).
A adição do farelo de vagem de algaroba no concentrado influenciou negativamente a produção e a eficiência de síntese microbiana (Tabela 6). Fonseca et al. (2006), em experimento com cabras lactantes e dietas com teores crescentes de proteína bruta (PB), compostas por $47 \%$ de silagem de milho e $53 \%$ de concentrado à base de fubá de milho como fonte de energia e uréia e farelo de soja como fontes de proteína, observaram eficiência de síntese microbiana de 69,2 a 85 g/kg de NDT pela equação de Chen \& Gomes (1992) e de 65,7 a 83,1 pela equação de Belenguer et al. (2002).

$\mathrm{O}$ valor para produção de PBmic das dietas contendo 0 e 33,3\% de farelo de vagem de algaroba $(85,89$ e 80,77 g/dia) foi semelhante ao obtido com a dieta contendo $13,5 \%$ de PB (81,2 g/dia) em trabalho de Fonseca et al. (2006), enquanto, para a eficiência de síntese microbiana, os níveis de 66,7 e $100 \%$ de farelo de vagem de algaroba foram os que mais se assemelharam aos obtidos por esses autores com as dietas contendo 13,5; 15,5 e 17,5\% de PB (média de 65, $1 \mathrm{~g}$ de PBmic/kg de NDT).

Produções de PBmic inferiores às observadas neste trabalho foram relatadas por Bomfim (2003), de 52,40 a $76,87 \mathrm{~g} / \mathrm{dia}$, obtidas por meio da técnica das bases de purina (relação N-total/ N-RNA) em estudo sobre o efeito da razão amido/ açúcares solúveis: fibra solúvel em detergente neutro $(0,82$ a 5,35\% na MS) em dietas para cabras lactantes.

Tabela 5 - Consumo de nutrientes em relação à matéria seca consumida em cada nível de substituição do fubá de milho pelo farelo da vagem de algaroba

\begin{tabular}{|c|c|c|c|c|c|c|c|}
\hline \multirow[t]{2}{*}{ Item } & \multicolumn{4}{|c|}{ Nível de farelo de vagem de algaroba $(\% \mathrm{MN})$} & \multirow[t]{2}{*}{$\mathrm{CV} \%$} & \multirow[t]{2}{*}{$\mathrm{r}^{2}$} & \multirow[t]{2}{*}{ Regressão } \\
\hline & 0 & 33,3 & 66,7 & 100 & & & \\
\hline Matéria orgânica & 91,63 & 91,37 & 91,41 & 88,33 & 1,64 & 0,65 & $\hat{\mathrm{Y}}=92,16-0,03 * * \mathrm{X}$ \\
\hline Proteína bruta & 11,13 & 10,67 & 10,59 & 10,08 & 8,56 & - & $\hat{\mathrm{Y}}=10,62$ \\
\hline Extrato etéreo & 3,62 & 2,36 & 2,38 & 1,65 & 23,50 & 0,86 & $\hat{\mathrm{Y}}=3,38-0,02 * * \mathrm{X}$ \\
\hline Fibra em detergente neutro & 38,54 & 41,96 & 45,03 & 47,95 & 3,76 & 0,99 & $\hat{\mathrm{Y}}=38,67+0,094 * * \mathrm{X}$ \\
\hline Fibra em detergente ácido & 19,67 & 23,31 & 26,97 & 32,33 & 8,30 & 0,99 & $\hat{\mathrm{Y}}=19,33+0,12 * * \mathrm{X}$ \\
\hline Carboidratos & 76,65 & 77,93 & 77,22 & 76,51 & 1,59 & - & $\hat{\mathrm{Y}}=77,08$ \\
\hline Carboidratos não-fibrosos & 38,12 & 35,85 & 32,19 & 28,56 & 3,50 & 0,99 & $\hat{\mathrm{Y}}=38,53-0,097 * * \mathrm{X}$ \\
\hline Nutrientes digestíveis totais & 65,35 & 67,78 & 64,44 & 64,60 & 11,10 & - & $\hat{\mathrm{Y}}=65,54$ \\
\hline
\end{tabular}

**Significativo a $1 \%$ de probabilidade pelo teste $\mathrm{F}$.

Tabela 6 - Equações de regressão ajustadas para a produção de proteína microbiana e a eficiência de síntese microbiana em cada nível de substituição do fubá de milho pelo farelo de vagem de algaroba

\begin{tabular}{|c|c|c|c|c|c|c|c|}
\hline \multirow[b]{2}{*}{ Item } & \multicolumn{4}{|c|}{ Nível de farelo de vagem de algaroba (\% MN) } & \multirow[b]{2}{*}{$\mathrm{CV} \%$} & \multirow[b]{2}{*}{$\mathrm{r}^{2}$} & \multirow[b]{2}{*}{ Regressão } \\
\hline & 0 & 33,3 & 66,7 & 100 & & & \\
\hline $\operatorname{PBmic}(\mathrm{g} / \mathrm{dia})^{1}$ & 102,32 & 96,21 & 81,57 & 72,57 & 32,35 & 0,98 & $\hat{\mathrm{Y}}=103,75-0,312 * \mathrm{X}$ \\
\hline $\operatorname{PBmic}(\mathrm{g} / \mathrm{dia})^{2}$ & 85,89 & 80,77 & 69,30 & 61,63 & 31,01 & 0,98 & $\hat{\mathrm{Y}}=87,03-0,253 * \mathrm{X}$ \\
\hline PBmic/NDT $(\mathrm{g} / \mathrm{kg} \text { NDT })^{1}$ & 108,77 & 96,78 & 82,24 & 78,57 & 30,24 & 0,95 & $\hat{\mathrm{Y}}=107,36-0,315^{*} \mathrm{X}$ \\
\hline PBmic/NDT $(\mathrm{g} / \mathrm{kg} \text { NDT })^{2}$ & 91,30 & 81,26 & 69,79 & 67,14 & 28,81 & 0,95 & $\hat{\mathrm{Y}}=89,96-0,252 * \mathrm{X}$ \\
\hline
\end{tabular}

* Significativo a $5 \%$ de probabilidade pelo teste $\mathrm{F}$.

${ }^{1}$ Chen \& Gomes (1992); ${ }^{2}$ Belenguer et al. (2002). 
Desde que mantidos outros parâmetros como suprimento de proteína degradável no rúmen e de minerais, entre outros, espera-se, em virtude do perfil de fermentação dos carboidratos solúveis em detergente neutro, que o crescimento microbiano tenha eficiência máxima. Portanto, Hall \& Herejk (2001) demonstraram que a produção de proteína bruta precipitada em ácido tricloroacético (proteína verdadeira), a partir da pectina $(28,1 \mathrm{mg})$ é menor que a do amido (32,5 mg), informação confirmada por Bomfim (2003), que demonstrou em caprinos que, tanto a eficiência de síntese quanto o fluxo de proteína microbiana para o abomaso, são menores em dietas mais ricas em fibra solúvel em detergente neutro, que são consistentes com os resultados encontrados neste estudo. Além disso, Bomfim (2003), trabalhando com níveis de 0,89 a 2,92\% para a razão amido + açúcares solúveis: fibra solúvel em detergente neutro da MS de dietas para cabras Saanen, reportou que essa variável afeta o metabolismo ruminal de proteína e observou maiores fluxos de proteína microbiana ao abomaso e eficiência de síntese microbiana nas dietas com maior participação do amido em relação à fibra solúvel em detergente neutro.

Vários fatores podem limitar taxas máximas de crescimento dos microrganismos, mas parece que a síntese de proteína é o mais importante. Substratos podem requerer diferentes rotas metabólicas (enzimas, proteínas transportadoras e outras) e considerável quantidade de aminoácidos pode ser desviada das atividades de crescimento para esse metabolismo específico. Esse fato foi demonstrado por Russell et al. (1979), que observaram que o crescimento de Butyrivibrio fibrisolvens foi maior em maltose, celobiose e sacarose que com glicose ou pentose. Acredita-se que certos substratos podem causar a ativação e síntese de certas enzimas que reduzem a produção de 5 '-adenosina trifosfato por unidade de tempo.

De acordo com Russell (1988), na fermentação de 1 mol de glicose até ácido acético, há um ganho líquido de 4 ATP, enquanto a fermentação de resíduos de pectina apenas 3, ou seja, $25 \%$ menos energia a partir de uma hexose, sem contar o custo energético da síntese de enzimas específicas como a 2-ceto-3-desoxi-6-fosfogluconato aldolase (KDPGA). A eficiência de síntese de proteína microbiana estimada em $\mathrm{g}$ de NMic/kg de NDT neste estudo para o concentrado com $100 \%$ de farelo de vagem de algaroba no concentrado foi aproximadamente $27 \%$ inferior ao daquele com $100 \%$ de fubá de milho no concentrado.

Essas evidências relacionadas à fonte de carboidratos e aos menores teores de carboidratos não-fibrosos das dietas podem explicar parcialmente a redução na síntese de proteína microbiana no rúmen das cabras alimentadas com níveis crescentes de farelo de vagem de algaroba. Portanto, dietas com alta proporção de fibra solúvel em detergente neutro na forma de pectina podem limitar o suprimento de proteína metabolizável de origem microbiana para o intestino delgado e requererem suplementação de fontes proteicas de baixa degradabilidade ruminal.

\section{Conclusões}

Mais pesquisas com uso de algaroba na dieta de ruminantes são necessárias, pois esse alimento reduz a relação acetato:propionato no líquido ruminal. A substituição do fubá de milho pelo farelo da vagem de algaroba em níveis superiores a $33,3 \%$ no concentrado compromete o fluxo de proteína microbiana ao intestino. A secreção de alantoína no leite não é um bom indicador da síntese de proteína microbiana em cabras, mas deve ser somada à excreção urinária de derivados de purina para não subestimar a absorção intestinal de bases púricas. A estimativa da síntese de proteína microbiana em cabras deve ser calculada por meio da excreção de derivados de purina a partir de equações obtidas com caprinos.

\section{Referências}

ANDRADE-MONTEMAYOR, H.; HERNÁNDEZ, F.; MADRID, J. et al. Comparison of different models to estimate purine bases absorbed in goats. South African Journal of Animal Science, v.34, n.5, p.28-30, 2004.

ANDRADE-MONTEMAYOR, H.; GASCA, T.G.; KAWAS, J. Ruminal fermentation modification of protein and carbohydrate by means of roasted and estimation of microbial protein synthesis. Revista Brasileira de Zootecnia, v.38, p.277-291, 2009.

BELENGUER, A.; YANEZ, D.; BALCELLS, J. et al. Urinary excretion of purine derivatives and prediction of rumen microbial outflow in goats. Livestock Production Science, v.77, p.127-135, 2002.

BELISAKIS, N.G.; TSIRGOGIANNI, D. Effects of dried citrus pulp on milk composition and blood components of dairy cows. Animal Feed Science and Technology, v.60, p.87-92, 1996.

BOMFIM, M.A.D. Carboidratos solúveis em detergente neutro em cabras leiteiras. 2003. 120f. Tese (Doutorado em Zootecnia) - Universidade Federal de Viçosa, Viçosa, MG.

CHEN, X.B.; GOMES, M.J. Estimation of microbial protein supply to sheep and cattle based on urinary excretion of purine derivatives: on overview of technical details. Aberdeen: Rowett Research Institute/International Feed Research Unit, 1992. 21p. (Occasional publication).

CORNELL NET CARBOHYDRATE AND PROTEIN SYSTEM CNCPS. version 5.0.18. Ithaca: Cornell University, 2002. (software).

FIGUEIREDO, M.P.; CRUZ, P.G.; COSTA, S.S. et al. Fracionamento dos carboidratos e componentes nitrogenados do farelo e diferentes partes integrantes da vagem de algaroba (Prosopis juliflora (Swartz D.C.). Revista Brasileira de Saúde e Produção Animal, v.8, n.1, p.24-31, 2007. 
FONSECA, C.E.M.; VALADARES, R.F.D.; VALADARES FILHO, S.C. et al. Estimativa da produção microbiana em cabras lactantes alimentadas com diferentes teores de proteína na dieta. Revista Brasileira de Zootecnia, v.35, n.3, p.1169-1177, 2006.

FOX, D.G.; SNIFFEN, C.J.; O'CONNOR, J.D. et al. A net carbohydrate and protein system for evaluating cattle diets: III. Cattle requirements and diet adequacy. Journal of Animal Science, v.70, n.11, p.3578-3596, 1992.

GUERRERO-CERVANTES, M.; RAMÍREZ-LOZANO, R.G.; MONTOYA-ESCALANTE, R. et al. [2007]. In vitro volatile fatty acid profile of shrub and cacti species selected by grazing goats. Disponível em: <http://adsa.asas.org/meetings/2007/ abstracts/0290.PDF> Acesso em: 12/11/2007.

HALL, M.B.; HEREJK, C. Differences in yield of microbial crude protein from in vitro fermentation of carbohydrate. Journal of Dairy Science, v.84, p.2486-2493, 2001.

LANA, R.P.; CAMARDELLI, M.M.L.; RODRIGUES, M.T. et al. Óleo de soja e própolis na alimentação de cabras leiteiras: consumo de matéria seca e de nutrientes e parâmetros de fermentação ruminal. Revista Brasileira de Zootecnia, v.36, n.1, p.191-197, 2007.

LEIVA, E.; HALL, M.B.; VAN HORN, H.H. Performance of dairy cattle fed citrus pulp or corn products as sources of neutral detergent-soluble carbohydrate. Journal of Dairy Science, v. 83, p.2866-2875, 2000 .

LINDBERG, J.E. Nitrogen metabolism and urinary excretion of purines in goat kids. British Journal of Nutrition, v.61, p.309-321, 1989.

MARTINS, A.S.; PRADO, I.N.; ZEOULA, L.M. et al. Digestibilidade aparente de dietas contendo milho ou casca de mandioca como fonte energética e farelo de algodão ou levedura como fonte protéica em novilhas. Revista Brasileira de Zootecnia, v.29, n.1, p.269-277, 2000.

NAGARAJA, T.G.; NEWBOLD, C.J.; VAN NEVEL, C.J. et al. Manipulation of ruminal fermentation. In: HOBSON, P.N.;
STEWART, C.S. (Eds.) The rumen microbial ecosystem. 2.ed. London: Blackie Academic \& Professional and Chapman \& Hall Publishers, 1997. p.523-600.

RIBEIRO JR., J.I. Análises estatísticas no SAEG (Sistema para análises estatísticas). Viçosa, MG: UFV, 2001. 301p.

RUSSELL, J.B.; DELFINO, F.J.; BALDWIN, R.L. Effects of combinations of substrates on maximum growth rates of several rumen bacteria. Applied and Environmental Microbiology, v.37, n.3, p.544-549, 1979.

RUSSELL, J.B. Energy yielding and consuming reactions. In: HOBSON, P.N. (Ed.) The rumen microbial ecosystem. London: Elsevier Science Publishers, 1988. p.85-215.

RUSSEL, J.B.; O'CONNOR, J.D.; FOX, D.G. et al. A net carbohydrate and protein system for evaluation cattle diets: I. Ruminal fermentation. Journal of Animal Science, v.70, n.11, p.3551-3581, 1992 .

SATTER, L.D.; SLYTER, L.L. Effect of ammoniaconcentration on rumen microbial protein production in vitro. British Journal of Nutrition, 32, n.2, p.199-208, 1974.

STROBEL, H.L.; RUSSELL, J.B. Effect of $\mathrm{pH}$ and energy spilling on bacterial protein synthesis by carbohydrate-limited cultures of mixed rumen bacteria. Journal of Dairy Science, v.69, n.11, p.2941-2947, 1986.

VALADARES FILHO, S.C.; MAGALHÃES, K.A.; ROCHA JUNIOR, V.R. et al. Tabelas brasileiras de composição de alimentos para bovinos. 2.ed. Viçosa, MG. UFV; DZO, 2006. 329p.

VIEIRA, P.F. Efeito do formaldeído na proteção de proteínas e lipídeos em rações para ruminantes. 1980. 98f. Tese (Doutorado em Zootecnia) - Universidade Federal de Viçosa, Viçosa, MG.

YU, P.; EGAN, A.R.; BOON-EK, L. et al. Purine derivative excretion and ruminal microbial yield in growing lambs fed raw and dry roasted legume seeds as protein supplements. Animal Feed Science and Technology, v.95, n.1-2, p.33-48, 2002 . 